\title{
The development and application of a triage system for urolithiasis during COVID-19
}

\author{
Gang Chen ${ }^{1} \cdot$ Hongyan $\operatorname{Ren}^{1}$ (1)
}

Received: 25 April 2021 / Accepted: 26 October 2021 / Published online: 11 November 2021

(c) The Author(s), under exclusive licence to Springer-Verlag GmbH Germany, part of Springer Nature 2021

\begin{abstract}
Purpose To balance epidemic prevention with the therapeutic needs of patients with urolithiasis during the COVID-19 pandemic, we developed a triage system to guide medical staff in making priority decisions.

Methods The study began with a review of the literature to propose a theoretical framework. Then, focus groups were assembled to develop, supplement, refine and form a consensus on the indications of the triage system. Finally, the system was implemented in the clinic. The validity and reliability of the system were tested by a content validity index and the interrater reliability kappa coefficient. Changes in patient characteristics and waiting time before and after the epidemic were compared. Results The theoretical framework was based on disease pathophysiology, including obstruction, infection, kidney dysfunction, and other symptoms. With this guide, a 28-item triage system with categories of T1-5 (low priority to urgent) was developed. The content validity index and the interrater reliability coefficient were 0.833 and 0.812 , respectively. During clinical application, although the total number of patients remained steady, the proportion of $\mathrm{T} 1$ decreased significantly; even though the overall waiting time of patients did not change significantly, it increased for T1 and decreased for T2-4 in 2020 compared with $2019(P<0.05)$.

Conclusion This triage tool based on the dimensions of obstruction, infection, kidney dysfunction, and other symptoms has good psychometric properties and significant utility for prioritizing patients with urolithiasis during times of crisis. With this system, patients of moderate to high priority were treated promptly during the COVID-19 pandemic.
\end{abstract}

Keywords Urolithiasis · COVID-19 · Triage · Psychological tests · Acute kidney impairment $\cdot$ Chronic kidney failure · Hydronephrosis

\section{Introduction}

Although the global case rate and mortality rate of coronavirus disease 2019 (COVID-19) have continued to decrease, the uncertainty of the variants of SARS-CoV-2 resulting in changes in transmissibility, clinical presentation and severity still challenge global healthcare. [1] The COVID-19 pandemic has changed not only the world but also medical practice. Limited resources, dynamic changes in the pandemic, and even potential risk of COVID-19 strained both patients and medical staff, further limiting the availability of necessary urological surgery.

\section{Hongyan Ren \\ 754743870@qq.com}

1 Department of Urology, The First Affiliated Hospital of Chongqing Medical University, No. 1 Youyi Road, Yuzhong District, Chongqing 400016, China
In response to this new and complex situation, many scholars have suggested triage systems with which to make priority decisions of patients in the interest of conserving hospital beds and personal protective equipment as well as keeping patients and health care workers safe. The American College of Surgeons (ACS) recommends that medical organizations apply to three categories and six-level protocols for nonemergency procedures. [2] International and European national urological associations have also issued prioritization strategies for oncological and non-oncological procedures. [3] There are also some recommendations specifically for the triage of urinary stones. [4-7] In these suggestions, many indications have been used to assess the urgency of diseases, such as stone size, obstruction, renal colic, infection, indwelling J-J stents, and kidney dysfunction. These rapid responses have greatly optimized urolithiasis practices. However, they merely synthesize recommendations and list a series of patient conditions; they still lack logistic 
organization and are incomplete. For example, urosepsis is listed as an emergency, but other stages of infection, such as uncontrolled complicated urinary tract infection (cUTI), are not taken into account. This may be due to the lack of a theoretical framework. A theoretical framework is the basis of an instrument that logically develops and connects sets of concepts and indications. It can provide a complex and comprehensive understanding of concepts. [8] A recent systematic review by Abdel et al. stated that the optimal triage system for urolithiasis is still unknown. [4]

The study aims to develop a triage system for urolithiasis based on a physiopathological framework of disease and to report on its usage in clinical practice during the COVID-19 crisis in our institution in 2020.

\section{Materials and methods}

\section{Triage system development}

According to the guidelines and literature review, [4, 9-12] we used examination, extract and cluster strategies to identify three common contributors to the prognosis of urolithiasis to form the basic framework: obstruction, infection, and kidney dysfunction. The priority of a patient depends not only on the degree of these factors but also on their mutual effects. This concept is more adequately represented as a three-dimensional matrix. See Fig. 1. However, these three dimensions cannot capture all the elements, and we added "other symptoms" as a supplement, such as pain, haematuria, and even indwelling stents.
We next inspected each dimension, further tiered and detailed indicators. To evaluate the degree of chronic urethral obstruction, we used the system for ultrasound grading of hydronephrosis (HN) introduced by the Society for Fetal Urology (SFU) (Supplementary Appendix 1). [13] The evaluation of kidney dysfunction includes acute kidney impairment (AKI) and chronic kidney dysfunction (CKD). For AKI, we used the definition and classification standards established by the AKI Network (Supplementary Appendix 2). [14] CKD was evaluated through the estimated glomerular filtration rate (eGFR) and graded according to the Improving Global Outcomes working group standard (Supplementary Appendix 3). [15] Urosepsis is defined as life-threatening organ dysfunction caused by a dysregulated host response to infection originating from the urinary tract and/or male genital organs. [10] We use the term cUTI to refer to an acute UTI with any features that suggest that the infection extends beyond the bladder, including fever (e.g., $>99.9^{\circ} \mathrm{F} / 37.7^{\circ} \mathrm{C}$ ), other signs or symptoms of systemic illness (including chills, rigors), flank pain, and costovertebral angle tenderness. [16] The risks of cUTI included nine common factors identified by the European Urology Association but not "obstruction at any site in the urinary tract", which was evaluated independently in this system. [10]

Then, we purposively stratified the recruitment of experts in our department by age and experience to ensure a diversity of perspectives. The inclusion criteria were as follows: (1) urologist; (2) $\geq 10$ years of professional experience; and (3) serves on an academic committee of urology. Ultimately, five urologists were enrolled. In addition to urologists, a head nurse, who was also a specialized urology nurse, was
Fig. 1 A three-dimensional matrix in which infection, obstruction and kidney dysfunction can be expected to influence the outcome of urolithiasis solely or mutually

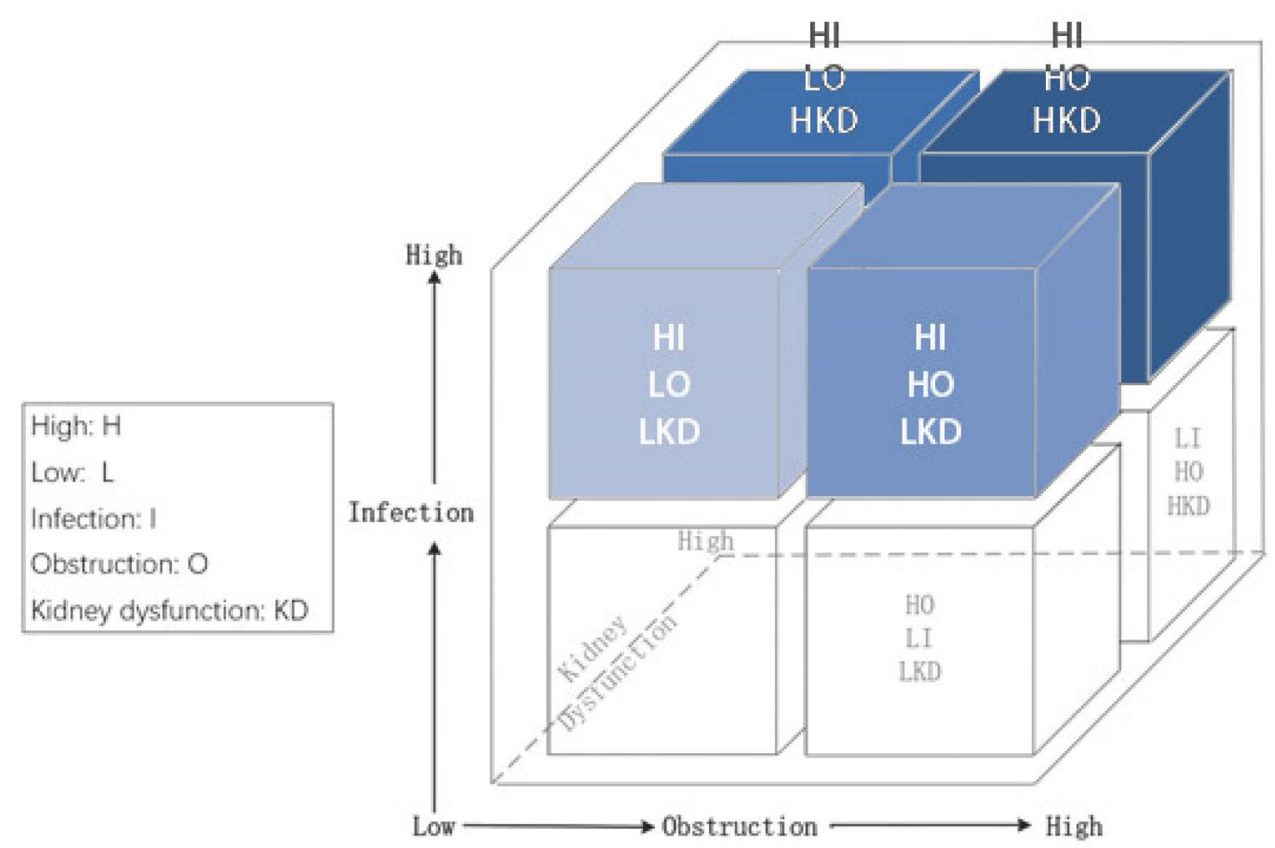


enrolled. The experts participated in two rounds of focus group meetings to organize, supplement, modify and form a consensus on the indications. After that, each of them was asked to evaluate the content validity index (CVI). Finally, a triage system consisting of five tiers and 28 indications was established. See Table 1.

\section{Clinical application}

Patients with urolithiasis in our department were consecutively enrolled from January 23 to August 31, 2020. The inclusion criteria were as follows: (1) age $\geq 18$ years, (2) urinary stones identified on ultrasound B or CT scan, and 3 ) considering hospitalization for active procedures. The exclusion criteria were as follows: (1) the first diagnosis was another disease, such as prostatic hyperplasia complicated with bladder calculi; and (2) patients gave up hospitalization. According to the government agency, the peak crisis of the city was from January 23 to March 25, when the whole city adopted strict lockdown control.

The doctors and senior nurses in the department were trained on patient triage. After the patient was scheduled for hospitalization, the following data were collected: (1) triage results, where the doctor and nurse graded the patients separately using the tool above; and (2) waiting time of the patient. For comparisons, the data from the same period in 2019 were retrospectively graded according to the medical records, and the waiting time was extracted from the registration center.

\section{Data analysis}

SPSS 20.0 and Excel were used for statistical analysis. The methods included the following:

1. A CVI, where six experts rated 28 items of the tool using a 4-point scale to obtain a total of 168 grades and the proportion of items given a rating of quite/very relevant, was computed.

2. Interrater reliability, where kappa was used to test the consistency between doctors and nurses.

3. Descriptive analysis, ANOVA, and the chi-square test.

4. The Kruskal-Wallis rank-sum test was used for two independent grading samples to test the difference in the proportion of triaged patients between 2019 and 2020 .

5. Student's $t$ test was used to compare the waiting time of each tier between 2019 and 2020.

Table 1 Triage system for urolithiasis

\begin{tabular}{|c|c|c|c|c|c|}
\hline \multirow[t]{2}{*}{ Tier } & \multirow[t]{2}{*}{ Definition } & \multicolumn{4}{|l|}{ Indications } \\
\hline & & Obstruction & Infection & Kidney dysfunction & Other symptoms \\
\hline T5 urgent & $\begin{array}{l}\text { Organ or life threat- } \\
\text { ening within } 24 \mathrm{~h}\end{array}$ & Anuria $>24 \mathrm{~h}$ & Urosepsis & AKI stage 2,3 & Life threatening \\
\hline T4 sub-urgent & $\begin{array}{l}\text { Organ or life } \\
\text { threatening within } \\
1-2 \text { days }\end{array}$ & $\begin{array}{l}\text { HN. G4, bilateral or in } \\
\text { solitary kidney }\end{array}$ & $\begin{array}{l}\text { cUTI antibiotic } \\
\text { therapy ineffec- } \\
\text { tive }>72 \mathrm{~h}\end{array}$ & AKI Stage 1 & $\begin{array}{l}\text { Severe and unmanage- } \\
\text { able }\end{array}$ \\
\hline T3 high priority & $\begin{array}{l}\text { Likely to cause } \\
\text { clinical harm if } \\
\text { treatment is post- } \\
\text { poned }>2-4 \text { weeks }\end{array}$ & $\begin{array}{l}\text { HN. G4; HN. G2, 3, bilat- } \\
\text { eral or in solitary kidney; } \\
\text { ureteral stone fails to } \\
\text { pass }>4 \text { weeks, }>0.8 \mathrm{~cm} \text {; } \\
\text { staghorn stone }\end{array}$ & cUTI & $\begin{array}{l}\text { CKD G4-5; CKD } \\
\text { G1-3 with soli- } \\
\text { tary kidney }\end{array}$ & $\begin{array}{l}\text { Moderate and unman- } \\
\text { ageable }\end{array}$ \\
\hline $\begin{array}{l}\mathrm{T} 2 \\
\text { Intermediate priority }\end{array}$ & $\begin{array}{l}\text { Likely to cause } \\
\text { clinical harm if } \\
\text { treatment is post- } \\
\text { poned }>4-8 \text { weeks }\end{array}$ & $\begin{array}{l}\text { HN. G2, } 3 \text {; ure- } \\
\text { teral stone fails to } \\
\text { pass }>2 \text { weeks, }>0.8 \mathrm{~cm}\end{array}$ & $\begin{array}{l}\text { Risk factors for } \\
\text { cUTI }^{\mathrm{a}}\end{array}$ & $\begin{array}{l}\text { CKD G1-3; upper } \\
\text { urinary stone } \\
\text { with solitary } \\
\text { kidney }\end{array}$ & $\begin{array}{l}\text { Mild and consist- } \\
\text { ent; ureteral stent } \\
\text { implanted }>1 \text { month, } \\
\text { planning for sec- } \\
\text { ondary opera- } \\
\text { tion; ureteral stent } \\
\text { implanted }>3 \text { months, } \\
\text { needs extraction }\end{array}$ \\
\hline T1 low priority & $\begin{array}{l}\text { Unlikely to cause } \\
\text { clinical harm if } \\
\text { treatment is post- } \\
\text { poned }>4-8 \text { weeks }\end{array}$ & HN. G1 & None & Normal & Asymptomatic \\
\hline
\end{tabular}

${ }^{a}$ Common factors associated with complicated UTIs [11]: (1) obstruction at any site in the urinary tract, (2) UTI in males, (3) foreign body, (4) pregnancy, (5) incomplete voiding, (6) diabetes, (7) vesicoureteral reflux, (8) immunosuppression, (9) recent history of instrumentation, (10) healthcare-associated infections 


\section{Results}

\section{Validity and reliability}

The content validity of the tool was 0.833 . Regarding the interrater reliability of the triage results between doctors and nurses, the kappa value was 0.812 (Supplementary Appendix 7).

\section{Clinical application}

From January 23 to August 31, 2020, a total of 809 patients were admitted. For comparisons, the data of 781 patients hospitalized during the same period in 2019 were retrospectively analyzed. The patient characteristics are shown in Supplementary Appendix 4.

Compared with the monthly average of 2019, the number of patients decreased dramatically in late January and February in 2020; in February 2020, it was 25.2\%, while in March 2020 , it recovered to $76.6 \%$ of the monthly average of 2019 ; from April 2020 onward, the number of patients exceeded the monthly average of 2019. In terms of the patient composition according to the triage category, the total proportions of T1 in 2020 and 2019 were $50.2 \%$ and $55.6 \%$, respectively, and the difference was statistically significant $(P<0.05)$. In contrast, the total proportions of urgent T4-5 in 2020 and 2019 were $4.7 \%$ and $4.9 \%$, respectively, and the difference was not significant $(P<0.05)$ (Supplementary Appendix 5).

The overall pre-admission waiting times of patients were 4.492 days in 2019 and 4.451 days in 2020 , showing no significant difference $(P>0.05)$. However, according to the stratified statistics, it was prolonged to 4.959 days for $\mathrm{T} 1$ but shortened to $0.866,3.599$, and 4.614 days for T4, T3, and T2, respectively in 2020; the difference among these categories was statistically significant $(P<0.05)$. Only in T5, the waiting time stayed unchanged (Supplementary Appendix 6).

\section{Discussion}

Urolithiasis is a common and costly disease in urology. [17] This report presents a theoretical framework-based triage system to determine the priority of patients with urolithiasis during a crisis. In this research, we begin with the proposal of a theoretical framework to provide a structure, focusing our attention on four aspects of disease progression: infection, obstruction, renal dysfunction, and other symptoms. In the following process of indication development, two rounds of focus group charrettes were conducted. Focus groups are group discussions exploring a specific set of issues. The advantages of focus groups are that on the one hand, they are efficient in the face of a sudden condition; on the other hand, the participants can interact directly to reach an agreement. [18] Validity and reliability are psychometric properties that are the basic need of a scientific instrument. The term "validity" denotes how well a measuring instrument measures what it purports to measure. Content validity presents a subjective judgment based on a review of the experts. As a prerequisite, a CVI of 0.80 or higher is acceptable by many academics. [19] In this research, the value of 0.823 showed that it was acceptable. Reliability refers to the "stability" of an instrument, statable measuring things in a reproducible fashion. The "stability" can be overtime or between raters. Kappa indexes are usually classified as good in the range of $0.60-0.80$ and very good in the range of $0.80-1.00$; in this study, the index was 0.812 , which indicated that this system was very stable.

Urinary tract obstruction is a common clinical problem associated with calculi. Proietti et al. [5] and Ian et al. [7] used the categories of "non-obstructing" and "obstructing" to classify patients. However, it can be very difficult to define "obstruction", as there is no clear division between obstructed and non-obstructed urinary tracts. [10] Doppler ultrasonography can distinguish between obstructive and nonobstructive pyelocaliectasis and measure the resistive index. For severity, the current practical evaluation uses the hydronephrosis grading system provided by the SFU, which has been used in many radiological and urological studies. [13]. Therefore, we incorporated this index into. Additionally, if the stone fails to pass through spontaneously more than 3-6 weeks, the obstruction may be suspected, and the cut-off size of stones is mainly $>1 \mathrm{~cm}$. However, Innes et al. also suggested that early intervention improves outcomes for patients with large (greater than $7 \mathrm{~mm}$ ) ureteral stones or 5-7 mm proximal or mid-ureteral stones. [20] For broader screening, we set this to $>0.8 \mathrm{~cm}$, also consistent with the recommendation by Ian et al. [7].

Urinary tract infections and urinary stones are strongly related. Infection is either the cause or the comorbidity of stones. The development of infection can complicate the management of pre-existing calculi. Urosepsis is undoubtedly the highest level of emergency. Moreover, UpToDate clinical consultation also recommends uncontrolled cUTI, such as that with a persistently high fever, as an indication for inpatient management. [16] Furthermore, for patients who are not currently infected, risk factors, such as diabetes, should also be taken into account during prioritization to prevent cUTI in the early stage. In summary, cUTI risk, cUTI development, ineffective cUTI antibiotic therapy, and urosepsis constituted an integrity chain in our system that was ignored by other recommendations.

Urolithiasis can impair kidney function. AKI as a clinical emergency is a consensus in many guidelines. However, in 
the current state, the triaged recommendations for urological diseases seldom make a further classification. Lee et al. found that the most important prognostic factors for renal outcome were AKI stage 2 or 3. [9] Therefore, we further triaged stage 1 as urgent to distinguish it from stage 2 and 3 of AKI as a sub-urgent status. Reports also suggest that $0.8-17.5 \%$ of nephrolithiasis patients had stage 2 of CKD or above. [21] It is uncertain how long a human kidney can tolerate an obstruction. In animals, recovery is proportional to the duration and degree of obstruction, and there is essentially no return of renal function after 6 weeks. [22] According to Tang et al., patients with mild to moderate renal failure showed maximal improvement in renal function forestalling or reducing need for dialysis/renal replacement therapy if appropriately treated. [21] Moreover, the Canadian Society of Nephrology patients with CKD recommended the therapy during the COVID pandemic to "adhere to previously established clinic visit schedules, where resources permit". [23] Therefore, to achieve the ultimate recovery of renal function, we recommend assessing pre-existing CKD as a priority.

Of course, the progression of urinary stones is too complicated to evaluate only through three pathology factors. To complement these, there are still "other symptoms", such as pain, vomiting, urine hemorrhage, and even the indwelling of a stent or other specific physical conditions. These conditions may not be life-threatening, but they have a certain impact on quality of life and need to be taken seriously [24]. It is worth noting the timespan of ureteric stenting in twostage surgical management, and the optimal dwelling time is less than 1 month, which is in accordance with the research results of Hanna et al. [25].

In general, urolithiasis-related obstruction, infection, kidney dysfunction, and other symptoms interact and co-occur. Renal dysfunction is caused by the degree and duration of the obstruction and the presence of infection; [26] in turn, obstruction not only accelerates the infection and deteriorates renal function but also causes other symptoms, such as pain and lower urinary tract symptoms. [9] From other aspects, these physiopathological conditions share the same risk factors, such as neurogenic bladder, previous obstructive nephropathy, urinary malformations, and diversions. Since these pathologies may not be synchronized, it is plausible to evaluate the priority of urolithiasis from these four dimensions.

From January to August 2020, the timeline of changes shows that the urological lithiasis ward was almost shut down in late January, immediately after the government announced the crisis. In February 2020, the peak of the crisis in China, the landscape of the urolithiasis ward changed with a significant shift in urgent and high priority cases but still sustained several low priority surgeries. This is slightly different from the research of Gokce et al., which suggests that it took at least 21 days for hospital regulations to evolve and for surgeons to adapt to the pandemic situation. [6] Since March 2020, with relief from the pandemic, the ward rebounded, and elective surgical treatments were rescheduled. These quick shifts may benefit from the rigid control policy of the government and the great capability of local medical resources.

The research also showed that the average waiting time of patients was not significantly different from that in 2019. However, the time was significantly shortened among the patients triaged T2-T4, while the time was significantly extended among $\mathrm{T} 1$. This indicated that, under the triage system, the higher the priority of patients, the more quickly they were admitted.

A recent review by Abdel et al. synthesized the published recommendations and triage systems $(n=14)$ in urology. [4] The included literature indicates that 4 previous studies made triage suggestions specifically for urinary stones. Regarding the level of triage, Proietti et al. [5] and Ian et al. [7]recommended four- and five-level prioritization schemes, respectively, while Fakhr et al. and [27] Almeras et al. [28] used three levels. From experience with other diseases, a five-level triage system is more reliable and discriminative than a three-level system. [29] Thus, we tend to use the five-level systems.

Compared with the former, our system mainly has the following advantages: first, it was built on a pathophysiological framework, and we always developed the indications under this guide; second, each factor was evaluated, and the sophisticated graded system such as AKI classification, CKD stage was incorporated; third, the additional classification of "sub-urgent" was added just below "urgent" to ensure greater accuracy in recognizing and responding to life-threatening conditions and, more importantly, to integrate with the COVID-19 control policy, which allowed patients classified as "sub-urgent" to receive more attention but stay out of the operating room for several hours until a PCR COVID test result became available.

Of course, in addition to timely and accurate disease triage, as other recommendations point out, dynamic monitoring and accounting for patient preference are also required. It is worth noting that the timeline of this system is a rough schedule that can dynamically change according to local conditions. The limitations of this system are as follows: on the one hand, it does not consider the patients' demographic factors, such as lung disease or cardiovascular disease; on the other hand, it was developed and tested in only one medical center, which was not in an epidemic area and did not face the threat of resource shortages; furthermore, the evaluation of the symptoms was subjective, whether need to incorporate the objective measures such as patient reported outcome measures (PROMs), [30] worth further research. 


\section{Conclusion}

In this manuscript, we proposed a urolithiasis triage system consisting of four factors: obstruction, infection, kidney dysfunction, and other symptoms. Implementation in the clinic for 8 months indicates its reliability and effectiveness. The system is characterized by the underlying pathophysiological framework, which is also presented as a visual figure. Although some of the indications are based on experts' opinions, indirect evidence, and pathology reasoning, we still feel that it has significant utility for urological lithiasis triage decisions that must be made to provide much-needed treatment during or after the COVID-19 pandemic. The next step may be to conduct well-designed research to generate more solid data verifying the validity of the triage.

Supplementary Information The online version contains supplementary material available at https://doi.org/10.1007/s00345-021-03871-7.

Author contributions HR contributed to the conception of the study and performed the construction of the triage system; GC contributed significantly to data collection, analyses, and manuscript preparation. All authors read and approved the final manuscript.

Funding None.

Availability of data and materials On reasonable request.

Code availability Not applicable.

\section{Declarations}

Conflict of interest The authors declare that they have no conflict of interest.

Ethical approval Ethical approval was obtained from the Research Committee of Chongqing Medical University (2020086), China.

Consent for publication Not applicable.

\section{References}

1. WHO (2021) Weekly epidemiological update on COVID-19-8 June 2021. https://www.who.int/publications/m/item/weeklyepidemiological-update-on-covid-19---8-june-2021. Accessed 23 June 2021

2. Surgeons ACo (2020) COVID-19: guidance for triage of nonemergent surgical procedures. https://www.facs.org/covid-19/clini calguidance/triage. Accessed 15 Nov 2020

3. Amparore D, Campi R, Checcucci E, Sessa F, Pecoraro A, Minervini A et al (2020) Forecasting the future of urology practice: a comprehensive review of the recommendations by International and European Associations on Priority Procedures During the COVID-19 Pandemic. Eur Urol Focus 6(5):1032-1048. https:// doi.org/10.1016/j.euf.2020.05.007

4. Abdel Raheem A, Alowidah I, Soliman M, Haresy M, Almozeni A, Althagafi S et al (2020) Urolithiasis treatment options during COVID-19 pandemic: review of current recommendations and triage systems. Afr J Urol 26(1):75. https://doi.org/10.1186/ s12301-020-00085-y

5. Proietti S, Gaboardi F, Giusti G (2020) Endourological stone management in the era of the COVID-19. Eur Urol 78(2):131-133. https://doi.org/10.1016/j.eururo.2020.03.042

6. Gokce MI, Yin S, Sonmez MG, Eryildirim B, Kallidonis P, Petkova $\mathrm{K}$ et al (2020) How does the COVID-19 pandemic affect the preoperative evaluation and anesthesia applied for urinary stones? EULIS eCORE-IAU multicenter collaborative cohort study. Urolithiasis 48(4):345-351. https://doi.org/10.1007/ s00240-020-01193-8

7. Ian S, Metzler M, Mathew D, Sorensen M, Robert M, Sweet M, Jonathan D, Harper M (2020) Stone care triage during COVID19 at the University of Washington. J Endourol 34(5):539-540. https://doi.org/10.1089/end.2020.29080.ism

8. Reeves S, Albert M, Kuper A, Hodges BD (2008) Why use theories in qualitative research? BMJ (Clin Res Ed) 337:a949. https:// doi.org/10.1136/bmj.a949

9. Lee EH, Kim SH, Shin JH, Park SB, Chi BH, Hwang JH (2019) Effects on renal outcome of concomitant acute pyelonephritis, acute kidney injury and obstruction duration in obstructive uropathy by urolithiasis: a retrospective cohort study. BMJ Open 9(11):e030438. https://doi.org/10.1136/bmjopen-2019-030438

10. EUA (2019) EAU guidelines on urological infections. https:// uroweb.org/wp-content/uploads/EAU-Guidelines-on-Urologicalinfections-2019.pdf. Accessed 10 May 2021

11. Esperto F, Prata F, Civitella A, Pang KH, Marchioni M, Tuzzolo $P$ et al (2020) Implementation and strategies to ensure adequate coordination within a Urology Department during the COVID-19 pandemic. Int Braz J Urol 46(suppl.1):170-180. https://doi.org/ 10.1590/S1677-5538.IBJU.2020.S122

12. Türk C, Petřík A, Sarica K, Seitz C, Skolarikos A, Straub M et al (2016) EAU guidelines on interventional treatment for urolithiasis. Eur Urol 69(3):475-482. https://doi.org/10.1016/j.eururo. 2015.07.041

13. Fernbach SK, Maizels M, Conway JJ (1993) Ultrasound grading of hydronephrosis: introduction to the system used by the Society for Fetal Urology. Pediatr Radiol 23(6):478-480. https://doi.org/ $10.1007 / \mathrm{bf02012459}$

14. Mehta RL, Kellum JA, Shah SV, Molitoris BA, Ronco C, Warnock DG et al (2007) Acute Kidney Injury Network: report of an initiative to improve outcomes in acute kidney injury. Crit Care (London, England) 11(2):R31. https://doi.org/10.1186/cc5713

15. Levin A, Stevens P, Bilous RW, Coresh J, Francisco A, Jong PE, Kidney Disease: Improving Global Outcomes (KDIGO) CKD Work Group et al (2012) KDIGO clinical practice guideline for the evaluation and management of chronic kidney disease. Kidney Int Suppl 2013(3):1-150. https://doi.org/10.1038/kisup.2012.73

16. Remi N, Polly E, Geraldine F (2020) Sepsis syndromes in adults: Epidemiology, definitions, clinical presentation, diagnosis, and prognosis. UptoDate. https://www.uptodate.cn/contents/sepsissyndromes-in-adults-epidemiology-definitions-clinical-presentati on-diagnosis-and-prognosis? search=urosepsis\&source=search result $\&$ selectedTitle $=1 \sim 150 \&$ usage_type $=$ default $\&$ display_ rank $=1$. Assessed 31 Jan 2020

17. Geraghty RM, Cook P, Walker V, Somani BK (2020) Evaluation of the economic burden of kidney stone disease in the UK: a retrospective cohort study with a mean follow-up of 19 years. BJU Int 125(4):586-594. https://doi.org/10.1111/bju.14991

18. Streiner DL, Norman G, Cairney J (2015) Health measurement scales: a practical guide to their development and use. Oxford University Press, Oxford

19. Polit DF, Beck CT (2006) The content validity index: are you sure you know what's being reported? Critique and recommendations. Res Nurs Health 29(5):489-497. https://doi.org/10.1002/ nur.20147 
20. Innes GD, Scheuermeyer FX, McRae AD, Law MR, Teichman JMH, Grafstein E et al (2021) Which patients should have early surgical intervention for acute ureteral colic? J Urol 205(1):152158. https://doi.org/10.1097/ju.0000000000001318

21. Tang X, Lieske JC (2014) Acute and chronic kidney injury in nephrolithiasis. Curr Opin Nephrol Hypertens 23(4):385-390. https://doi.org/10.1097/01.mnh.0000447017.28852.52

22. Gandolpho L, Sevillano M, Barbieri A, Ajzen S, Schor N, Ortiz $\mathrm{V}$ et al (2001) Scintigraphy and Doppler ultrasonography for the evaluation of obstructive urinary calculi. Braz J Med Biol Res 34(6):745-751. https://doi.org/10.1590/s0100-879x20010006000 07

23. White C, Kappel J, Levin A, Moran S, Pandeya S, Thanabalasingam S (2020) Management of advanced chronic kidney disease during the covid-19 pandemic: suggestions from the Canadian Society of Nephrology COVID-19 Rapid Response Team. Can J Kidney Health Dis 7:205435812093935. https://doi.org/10.1177/ 2054358120939354

24. New F, Somani BK (2016) A complete world literature review of quality of life (QOL) in patients with kidney stone disease (KSD). Curr Urol Rep 17(12):88. https://doi.org/10.1007/ s11934-016-0647-6

25. Hanna B, Zhuo K, Chalasani V, Vass J, Rasiah K, Wines M et al (2021) Association between ureteric stent dwell time and urinary tract infection. ANZ J Surg 91(1-2):187-191. https://doi.org/10. 1111/ans. 16414

26. Gambaro G, Croppi E, Bushinsky D, Jaeger P, Cupisti A, Ticinesi A et al (2017) The risk of chronic kidney disease associated with urolithiasis and its urological treatments: a review. J Urol 198(2):268-273. https://doi.org/10.1016/j.juro.2016.12.135

27. Fakhr Yasseri A, Aghamir SMK (2020) Urinary stone management during the COVID-19 pandemic: a suggested approach and review of literature. Ther Adv Urol. https://doi.org/10.1177/17562 87220939513

28. Almeras C, Denis E, Meria P, Estrade V, Raynal G, Hoznek A et al (2020) Recommendations of the Urolithiasis Committee of the French Urology Association for the management and the treatment of the stone formers patients during the COVID-19 pandemic crisis. Prog Urol 30(8-9):426-429. https://doi.org/10. 1016/j.purol.2020.04.021

29. Kuriyama A, Urushidani S, Nakayama T (2017) Five-level emergency triage systems: variation in assessment of validity. Emerg Med J 34(11):703-710. https://doi.org/10.1136/emerm ed-2016-206295

30. Mehmi A, Jones P, Somani BK (2021) Current status and role of patient-reported outcome measures (PROMs) in endourology. Urology 148:26-31. https://doi.org/10.1016/j.urology.2020.09. 022

Publisher's Note Springer Nature remains neutral with regard to jurisdictional claims in published maps and institutional affiliations. 